\title{
Violence and Creation: The recovery of the body in the work of Elaine Scarry
}

\begin{abstract}
Elaine Scarry's book The Body in Pain justly deserves it place as one the pivotal works that opened up the field of 'body studies'. The text needs to be evaluated in the retrospective terms of the field it established, and also with respect to the changing status of both 'torture' and 'war' in contemporary state politics.

Scarry's analysis of the relationship between making and unmaking, tools and weapons, under-estimates the reversibility and the situated relational character of these processes and artefacts. The changing nature of modern conflict, and the rising concern with global terrorism rather than 'conventional' and 'nuclear' war, makes the 'referential instability' of the body difficult to recuperate in postconflict discourse. At the same, the normalisation of the logic of torture in the contemporary governance of the bodies of the most vulnerable in society makes Scarry's analysis all the more prescient.
\end{abstract}

Keywords: Body studies; making; war; torture; material culture

\section{Introduction}

I don't recall when I first became aware of Elaine Scarry's magisterial work, The Body in Pain. Scrutinising the inner cover of my battered copy, I can see that it seems to have come to me second-hand, a happy outcome of the practice of scouring second-hand bookshops that characterized doctoral studies in the humanities and social sciences in the now unimaginable period of academic work BI (Before-Internet). But I certainly recall, still vividly, the impact of reading this densely argued, yet undeniably 'live' text. Embodiment placed at the very centre of social theory, as the ground for reflecting upon how the psychological is extended into the world, in myriad ways. Making and technique as fundamental human activities, whose enactment doubles back to reshape and recreate what it means to be human. Power as directly modulated through the body, whose legitimacy is grounded in nothing other than its ability to seemingly lift corporeal predicates out of their locus and attach or arrange them in broader discourses. These are ideas with an enormous and ongoing appeal.

The flow of Scarry's argument is, perhaps by design, overwhelming. There are two substantive sections and six chapters. But these are broken down into endless lists of points. There will be 'two paths', 'three vocabularies', 'four attributes', 'five positions'. Scarry is continuously stating and re-stating her argument in all its utter clarity - that sentience is bodied-forth into the world through the making of artefacts - whilst simultaneously dividing and decomposing it into a swarm of sub-arguments. At one point she likens the overall text to the act of building 'a large and miraculous suspension bridge', before describing the pages that follow as 'the equivalent of describing, for example, the character of the metal in a few of its pins or the pressure in its weave of cables in small section of its gigantic tracery' (Scarry, 1985: 281). The image of the author as the engineer who can imagine the grand project, but is obsessively engaged with endlessly fixing the small details remains irresistible. 
It is in these small details that Scarry is most convincing and intimidating. Chapter 4, which occupies nearly a third of the book, demonstrates that Scarry can quote authoritatively from the Old and New Testament, that she has a 'feel' for the contours of these texts and their modes of argumentation. But the chapter, perhaps sensing just how far it has tacked in one direction, abruptly shifts to an extended discussion of Marx's Capital, reflecting on its final structure and the possible structures that it might have taken, based on the evidence of the Grundrisse. This strange ranging between what appear to be the two opposite poles in the spiritual-materialist dimension is striking, not least because of the deeply unfashionable nature of demonstrating a reasonably detailed grasp of Marx in the North American academy of the late 1970s/early 1980s. And it is here that Scarry makes what is, I think, perhaps the boldest claim in the entire book, that the Judeo-Christian scriptures and Capital are 'companion texts' (p. 277), that the forms of 'wounding and creating' found in the Old Testament as 'solutions' to the problem of substantivizing God 'now itself recurs within the material realm' described by Marx (p. 257).

Perhaps only a tenured literary scholar could have made such a claim at the time. It is worth noting that the 'turn to the body' which Scarry's work presages was predominantly a literary-historical phenomenon. The humanities journal Representations first appeared in 1983 as Scarry was finishing up her manuscript. The historian Thomas Lacquer's Making Sex was published five years after The Body in Pain, roughly co-extensive with the three volume Fragments for a History of the Human Body (by which time, the floodgates for 'body' books were well and truly open). What differentiates Scarry, however, is that she expands the canon of literary interpretation to include apparently non-literary sources. These include diverse materials such as the McGill Pain Questionnaire, Amnesty International campaign materials, reports on torture, trial transcripts of personal injury cases and so on. These become woven together in an argument that is both transcendent in its formulation - making is the means of human selfextension, and hence the very grounds of 'civilization' - and worked out in relation to specific contemporary conditions (e.g. torture, nuclear war, product liability laws).

Inevitably this double articulation of the argument as set against the grand vista of the civilizing process and current events in the latter quarter of the twentieth century, as they show up to the North American humanities, now seems somewhat problematic. Scarry's use of the contemporary materials is rather uneven. The engagement with medical practices of pain management is fleeting and confined merely to the introduction (compared with sixty pages on the scriptures). The work on trial transcripts is tucked away inconsequentially in the final chapter. There is a sense that the final manuscript retains these prior projects for biographical reasons rather than for those of advancing the argument. More significantly, Scarry is concerned with the rhetorical spectacle of nuclear war (i.e. what the logic of mutually assured destruction does to the political) in a way that now seems anachronistic. The nature of 'war', which is so crucial to the first part of the book, seems to have radically shifted in a post 9/11 world. Terrorism, which for us now weighs heavily on any discussion of state and non-state conflict, is entirely absent as a phenomenon in the text. At one point Scarry - quite reasonably - reflects on a world after the fall of the Berlin 
Wall, which she sees as potentially some generations away, rather than, as it came to pass, four years later.

As scholars we write from where we are right now, without the gift of clear foresight. The Body in Pain is a book that is both of its time, and part of an extensive canon of work brought into being by its own appearance. We cannot but read this text from the perspective of the 'body studies' that it helped to inaugurate. And it is in relation to this tension between the situated and the imaginative creation of a field of studies that I want to understand the contemporary relevance of the book. What does Scarry's text create - how does it body-forth a set of intellectual 'objects' which have to some extent acquired their own autonomy? How do these objects reciprocally act back on the conditions under which they were produced? In other words, what, with the benefit of hindsight, do the terms of Scarry's argument do to the key examples of 'unmaking' and 'making' (e.g. torture, war, belief, capital) from which it originates?

In homage to Scarry's preference for numerical specificity, I will work through three themes in addressing the questions above. The first concerns the 'deconstructed' relation between pain and imagination and its 'positive determination' that divides and unites the first and second parts of the book. Scarry's argument depends upon demonstrating that the former inversely exemplifies the latter, hence the counter-intuitive positioning of the two parts. However, what if the deconstructed relation destabilizes the positive determination - could the routinisation of torture, for example, not merely be the awful doppelganger of human creative capacities, but also seriously pervert the way we think about creation and imagination?

Second, one of the great achievements of Scarry's argument is to exemplify the claim that the creation of artefacts acts back on human creativity (this, Scarry suggests, is what is meant by 'civilization'). The artefacts in which our sentience becomes embedded transform us. Yet artefacts are also characterized by a kind of referential instability - what is created can appear to disown the conditions or the labour out of which it is constituted, as Marx demonstrated. Could this referential instability migrate to the human body itself, such that what holds for the artefacts through which self is extended, can also come to destabilise our relationship to our embodiment? Scarry hints at this possibility in her discussion of intervention at the corporeal level, but the implication must here be that the 'body' separated from the object world by the agony of pain may itself be a fatally unstable referent.

The third theme is around the relatively under-theorised conception of justice that runs throughout Scarry's text. Issues of scale and mass play an important role here. Scarry claims that relationship in the Old Testament between creative powers (i.e. humans) and created power (i.e. God) is underpinned by the expansion of the biblical population (hence the obsessive enumeration of 'begetting'). Similarly, she observes in Capital, a movement towards mass labour and the circulation of commodities. Injustice names the process where the reciprocal action of the created on the creator serves to limit rather than expand their collective powers, or transfers its benefits to a reserved proportion of the 
mass. We might however enquire as to the nature of the presumed collectivity upon whom notions of justice are being grounded - is the capacity to transform and expand human powers an unalloyed good? Moreover, in what ways do efforts to intervene and enact forms of distributive justice intersect with the 'deconstructed' version of the relationship between pain and imagination and how might this impact upon the value placed upon 'making'?

\section{The Positive Determination - Making}

Scarry's text presents the 'deconstructed' version of making before its positive determination. This is an odd choice, since it asks the reader to understand how the creative process can be abused to consolidate political power before its 'world-making' formulation is established. It may be that this way of structuring the argument is done to avoid the implicit suggestion that torture and war are exceptional, instead of the routine debasement of creation. Rather, from its very beginning, violence is inherent in the desire to externalize human sentience in the object world. This is certainly the way in which Scarry reads the Old Testament, where the God who is created piece-by-piece through the Covenant and the recurrent punishments visited on the faithful often appears as a weapon rather than a tool. Nevertheless, it is important to reverse the order of the text in order to appreciate the full reach of the making/unmaking argument.

It is difficult to imagine what constitutes human existence as somehow outside the created 'object-world'. The significance, for Scarry, of pain is that it is the sole human experience that in its intensity is 'word-annihilating'. The body-in-pain knows no other object than its own agonizing corporeality. The objects which inflict pain on the body recede before the pain that becomes all consuming:

It is intense pain that destroys a person's self and world, a destruction experienced spatially as either the contraction of the universe down to the immediate vicinity of the body or as the body swelling to fill the entire universe. (p. 35)

The converse of this statement is that the movement that takes us beyond a 'contraction' to our own body is one that extends outward into the material world. For Scarry, the growth of human sentience is found in its progressive expansion beyond the limits of the body. A chair, for example, enables the continuous adjustment of the weight of the body to be transferred to a part of the environment. Similarly, the role of shelter is to make thermo-regulation no longer a pressing immediate concern. In both cases, the design of the artefact chair, blanket, roof and wall - has the shape and functioning of the human body written into its very structure. The body is present in artefacts in such a way that we can retrospectively 'recover' the shape and press of bodies in the objects emanating from cultures at a historical remove from our own (see Fisher, 1978). These traces hint at the 'dis-embodying' power of artefacts. A cup, for example, mimics the way that hands are brought together to bring water to the mouth, but it also replaces the need for hands to routinely be 'cupped' in this way. The artefact then extends embodiment through mimicry (i.e. 'bodies forth') and substitutes for embodiment through its own created attributes (i.e. 'disembodies'). 
Examples such as chairs and blankets only begin to hint at the range of modifications to the world that making accomplishes. The chair seems to mimic the skeletal structure of the human body, with vertical and horizontal lines of support intersecting around a pivotal point. But what of artefacts that do not seem to refer back to the body - the wheel, for example, or at a more complex level, the steam engine? Such artefacts allow us to grasp the crucial role of imagination - the ability to envisage an object outside of existing corporeal experience. Much as the making of artefacts bodies-forth and extends human capacities, so it also involves a projection of imagination outside of the limits of the body. In this sense, Scarry sees 'pain' and 'imagination' as the two 'counterpoints' to intentionality - 'physical pain ... is an intentional state without an intentional object; imagining is an intentional object without an experienceable intentional state' (p.164). The key term which links the two points is 'work' ${ }^{\prime}$, which is understood as the embodied process that diminishes pain through creating artefacts which support and extends the capacities of the body, and which externalizes and objectifies imagination in 'fragments of world alteration' (p. 171).

It is through 'work', Scarry argues, that we become entwined in the corporeal extensions and imaginations of one another:

Through tools and acts of making, human beings become implicated in each other's sentience. Seeing is seeing of $x$, and the one who has made the ' $x$ ' has entered into the interior of the other person's seeing, entered there in the object of perception ... Thus when intentional objects come to include not just the rain, berries, stones and the night but also bread, bowls, church steeples, and radiators, there comes to be an ongoing interaction at the (once private) center of human sentience; for not only are the interior facts of sentience projected outward into the artifact in the moment of its making, but conversely those artifacts now enter into the interior of other persons as the content of perception and emotion. ( $p$. 176)

We recognize our thoughts, desires and values - that is, our sentience - through the ways in which work objectifies these things in the world around us. Mutual orientation to this objectified sentience in the 'interior structure of the object' is what constitutes the sociocultural world. For example, different techniques and artefacts for transporting infants provide some insight into the ways that adultchild relationships are configured. The use of baby carriers or papooses suggest that infants are considered in terms of their proximity to the adult body, that 'closeness' is a desired quality, whereas mechanical pushchairs and prams render transportation as a question of relative mass and force akin to moving other objects (e.g. food). The more highly elaborate the artefacts become (e.g. church steeples), the greater the interpretative work required to 'recover the body' from within their structure.

It is at this point that the separation of making from unmaking (part 2 from part 1 of the book) becomes an issue. Scarry distinguishes between artefacts that function as tools and those that function as weapons. A tool is applied to the world in a uni-directional fashion to project sentience into a created artefact (e.g. 
a needle and thread sews together fabric to make a coat to keep a human body warm). By contrast, a weapon implies acknowledgement of the sentience of another, which it seeks to relieve through its own functioning (e.g. a gun allows one person to threaten or remove the other's capacity to act whilst remaining at a distance). Tools and weapons therefore imply different assumptions about sentience and create different relational structuresii. Tools are emblematic of making, weapons of unmaking. Yet, whilst some types of artefact more firmly belong to one category rather than the other (e.g. it is difficult to treat a gun as anything other than a weapon), many have an ambiguous status. The Ani DiFranco lyric 'every tool is a weapon if you hold it right' (from $M y I Q$ ) ${ }^{\mathrm{iii}}$ neatly captures this reversibility. It also speaks to a more profound sense in which the use (rather than the inherent structure) of artefacts and the projects of making and unmaking can be difficult to disentangle.

For example, Reviel Netz's (2004) cultural history of barbed wire traces how this mundane, omnipresent, yet brutal technology was invented and transformed in its use. Originally developed as an agricultural technique for managing the expansion of lifestock across areas too large to be managed by human presence, barbed wire becomes re-purposed in war as a device for interrupting movement across the battlefield, and latterly as a means of containment within concentration camps. The primary referent moves from cows to horses to human bodies. Now, whilst sentience is implied across this chain - positioning barbed wire a 'weapon' in Scarry's sense - the relationship between the technology, the land in which it is deployed, and the movements between bodies that are supposed within that space are completely different. Whilst we can say of the story that Netz tells that it may start with 'making' and end with the most grotesque 'unmaking', these two points do not exhaust the enormous variety of 'world altering' ways that barbed wire has become part of the modern world.

To grasp how and in what ways a technology or technique supports the project of 'making' or 'unmaking', we need to shift to from an ontology premised on the interior structure of the object to a relational ontology (see Mol, 2002). Here the predicates of an artefact do not simply inhere within the process of its creation, but rather in how the artefact becomes embedded in a network of reciprocal actions and significations. Langdon Winner's (1980) well known examples of Robert Moses' architectural restructuring of New York are a good example (see also Caro, 2015). Drawing on sources remarkably similar to Scarry's (e.g. Marx, Engels), Winner argues that Moses attempted to embed a particular version of social relations in the design of the city. The emphasis on multi-lane roads throughout Manhattan, for example, made the car, and hence a particular ideological version of social mobility, the dominant code. The bridges constructed across the freeways leading out of the city to Long Island were notoriously constructed to prevent public buses passing under them, thus making beaches inaccessible to the urban poor (i.e. black Americans). Is the bridge then a tool (for extending the routes out of the city) or a weapon (designed to inflict pain on the urban poor)? Doubtless it is both, but we cannot understand how it is either one or the other without tracing a complex network of design, architectural codes, capital, racism, cars, buses, concrete and many other things besides. Making and unmaking are here entangled in a complex and unfinished - spiral. 
Rather than treat making and unmaking are contrasting projects, we may then see them instead are reciprocally bound in the sociotechnical trajectory of a given setting (see Latour, 1992 on 'action' and 'counteraction'). For example, the urban poor in London, as in many other major cities, are increasingly subject to a range of strategies and techniques, from the juridical to social welfare to architectural, designed to limit and manage their mobility. One prominent recent technology is 'defensive architecture' - the design of the built environment to hinder rough sleeping through benches that do not allow the body to be fully prone and 'anti-homeless spikes' mounted in doorways that threaten to injure those who would otherwise rest in the space. The appearance of this technology has been met with a counter-movement of activists placing mattresses on the spikes, transforming a potential weapon into a means of securing bedding in place. Moreover, the changing landscape of the urban environment has increasingly led rough sleepers to explore alternative locations such as parks and green spaces, which can be territorialized in spaces for living through use of basic or improvised camping equipment. Here we can see that the capacity for 'world alteration', whilst unevenly distributed, does not neatly follow a single channel.

\section{The Deconstructed Version (i) - Unmaking in War}

The chapter on 'The Structure of War' dominates the first part of the book. Here Scarry calmly and resolutely details at considerable length the various attempts to justify the carnage of modern warfare. From the outset, her central claim is clear that an explanation that begins anywhere else than with the colossal destruction and maiming of the human body is illegitimate and self-deluding in its premises:

The main purpose and outcome of war is injuring. Though this fact is too self-evident and massive to ever directly be contested, it can be indirectly contested and disappear from view by simply being omitted: one can read many pages of a historic or strategic account of a particular military campaign, or listen to many successive instalments in a newscast narrative of events in a contemporary war, without encountering the acknowledgement that the purpose of the event described is to alter (to burn, to blast, to shell, to cut) human tissue, as well as to alter the surface, shape, and deep entirety of the objects that human beings recognize as extensions of themselves. (p. 64)

The language of war is one of deep denial. It ranges across talk of 'surgical strikes' and 'collateral damage' to that of 'attacking the underbelly' and 'punching on the nose'. That so much of it should contain corporeal imagery that is translated to gigantic imaginary collective opponents - as though it were mighty giants that assaulted one another instead of vast arrays of actual, living fragile human bodies in the process of being crippled and annihilated - speaks to the disconnect between how war is spoken about and subsequently represented (in endless 'newscast narratives') and how it is physically experienced by those who become enveloped by it (Hoskins, 2004).

This denial becomes Scarry's point of entry - what, in its essential structure, does war actually consist of? Her answer is that it has two core elements. Firstly, 
war is a contest, and secondly, it involves one side attempting to out-injure the other side. At first glance, the second part appears to be the medium through which the first is accomplished and enforced. In a tone of deliberate provocation, she asks why nations that are apparently so rich in their cultural and intellectual resources should settle disputes in so barbaric a manner. Would not an organized sporting event suffice? Or perhaps even a bake-off? Why select war as the form for a contest? One immediate answer is that unlike the Olympics or Masterchef, war appears to deprive the loser of the resources to contest the outcome - 'a military contest differs from other contests in that its outcome carries the power of its own enforcement; the winner may enact its issues because the loser does not have the power to reinitiate the battle' (p. 96). It is because the losing side has been 'out-injured' that they lack the physical capability to either dispute matters further or re-start the conflict. In this way, injuring as a mode of conducting contests 'brings about the cessation of its own activity' (p. 96).

However, as Scarry goes on to show, this 'power of its own enforcement' argument is not secure and can be falsified by historical facts. It is often not the case that the losing side is physically unable to continue the conflict, rather that that they feel unable to go on. In this sense, out-injuring leads to an imagined self-enforcement - 'once the war ends it will be as though war carried the power of its own enforcement, and it is the 'as though', mechanism, the 'as if reflex, that may at last expose the terrifying resources of war as two populations assume their respective designations as 'winner' and 'loser"' (p. 108). The problem becomes one of ensuring that belief - the 'as though' mechanism - becomes translated into a shared reality.

The objectification of belief into an agreed outcome turns on the referential instability of the body. Colossal loss of life and the wounds born by a significant proportion of the surviving population can be ambiguous signs. They can be justification of a hard-won victory, markers of a fatal and illegitimate conflict, symbols of the need to remember 'never again' or many other things. Neither the dead nor the maimed body clearly points to any given discourse. But this referential instability means that bodies can be moved around semiotically, that the very lack of a clear referent makes them available to arguments which claim to restore to incomprehensible loss some manner of meaning:

[I]njuring not only provides a means of choosing between disputants, but also provides, by its massive opening of human bodies, a way of reconnecting the derealized and disembodied beliefs with the force and power of the material world. (p. 128)

In luminous phraseology, Scarry speaks of how bodies are laid 'edge to edge' with the language of post-conflict. The experience of suffering, the pain and disconnection of violence creates the conditions where dead and injured bodies are subsequently recruited into the discourse of 'victory' and 'loss', where they reacquire their material force. That this discourse is always a convenient cultural fiction matters less than the fact of its accomplishment. Moreover, once this recruitment is enacted, the memory of semiotic settlement becomes emblazoned on the body - 'what is remembered in the body is well remembered' (p. 110). We 
cannot but recall that the millions of dead and wounded now mean this, and will do so in perpetuity. To think otherwise, to draw attention to the semiotic manoeuvres that have laid claim to the bodies (such as by calling into question whether one should wearing a poppy), is to risk being seen to have denied their (new, accomplished) brute reality.

The examples of war that Scarry uses The Body in Pain date back to a little over 100 years of the time of its publication. They are, for the most part, instances of what is inelegantly termed 'conventional warfare' (e.g. the two 'world wars', Vietnam, Korea, the US civil war, etc.). It is noticeable, by contrast, that many of the conflicts in South America which are now seen as 'proxy wars' fought by the US through intermediaries form the basis of the separate chapter on torture, rather than being given the status of 'war' in her analytic framework. To reiterate, few of us can see into the future with sufficient clarity to be able to critique a work that makes no such claims. But the changing nature of how we currently view war, and what this has done to the way we now reflect on the conflicts of the twentieth century is relevant to how we can connect, thirty years later, to Scarry's argument.

A good starting point here would be with both the absolute figures for death and the ways in which these are attributed in modern conflicts. The Iraq conflict, for example, nominally lasted for a little under two months in 2003, but the period of 'actual war' is usually seen as one phase in a more extended period of conflict. Between 2003-2010, the Iraq Body Count Project lists 174,000 Iraqi dead, roughly two thirds of whom were civilians (https://www.iraqbodycount.org). By contrast, there were 4,425 deaths of US forces (with the asymmetrical nature of the conflict meaning no direct loss of life to US civilians) - a 40:1 ratio. Compare this with roughly 60 million deaths in World War II, with over half this figure attributable to the Soviet Union alone. Turning from the gross figures to their composition, the Iraq conflict offers a less clear distinction between combatants and civilians, since it is complicated by 'insurgents', 'security forces' and 'nonhostile fire' (which accounts for 1,000 of the total US dead). Of particular note is the category of 'contractors' $(1,487)$, who are not easily counted as 'representatives of the state' but rather commercial agents to whom the work of conflict is out-sourced. Whilst not denigrating the horror of a single death, it is clear that the logic that will be required to lay this highly varied mixture of dead bodies 'edge to edge' with a coherent discourse will be far more complex than the kind discussed by Scarry, as the lack of any coherent generally accepted narrative of the meaning of that period demonstrates.

If the picture has changed for those forms of conflict that still bear the term 'war', then what of those prolonged exchanges of violence that are grouped under the title 'terror'? As the ongoing public debates in the Global North around the crisis in Syria and the rise of Islamic State (IS/ISIS/Daesh) show, a major part of the problem comes from being able to actually name who the opposing sides in this conflict are, their relative numbers, and the complex relationships between them. At the heart of such conflicts are, as ever, the brute cruelty of death and injury, inflicted on civilians and combatants alike, and with the kinds of ratios that are to be expected when nations of the Global North throw their militarytechnological might against the populations of the Global South. But the role of 
the body seems to have changed considerably here, in part due to changes in media technology and its corresponding management by the differing sides. On the one hand, the management of the repatriation of war dead is now managed to far greater degree than in previous conflicts. Media report focus more on images of the living person rather than the dead bodies, coffins and funerals (Hoskins \& O'Loughlin, 2013). On the other, the threatened and actual death of a given individual is given far greater prominence - as with the circulation of videos of the beheading of hostages. In both cases the referential instability of the body, which acts, in Scarry's argument, as a precondition to the subsequent semiotic resolution of conflict, is effaced during the conflict itself. There is not much ambiguity to be had in a Facebook image of a smiling soldier with his children or in the horror of a filmed execution. Very little is held over for future appropriation.

A further difference is with the meaning of civilian casualties in acts of terrorism. In his study of the 2005 London Bombings, The Labour of Memory, Matthew Allen describes the problems that emerged at the initial commemorative event held in St Paul's Cathedral. Front row seats were given to politicians, whilst injured survivors of the bombings were assigned to side seats, which placed them outside of the main media focus. The referential instability of the injured body of the survivor was clearly an obstacle, rather than a resource, to the political narration of the event that was emerging at the time, which had to navigate the counterfactual notion that prior military action in a faraway country was actually a means to ensuring national security. The maimed bodies spoke otherwise and therefore needed to be pushed to the margins. Interestingly, different decisions have been made in the recent services around the 2015 Paris attacks, where wounded survivors have been placed at the very centre of the initial commemorative events, reflecting perhaps different recent historical and political trajectories across the two nations.

We may then say that that there have been three critical changes in the nature of 'war' which alter our relationship to Scarry's analysis. First, that major conflicts are not as neatly bounded as they once were, hence the moment at which bodies can be recruited into post-conflict discourse has been replaced with a constant tugging at the referential instability of bodies throughout the entire course of conflict, with no clear resolution. That is to say that rather than the violence of war deliberately creating a spectacle of shattered bodies that are subsequently recruited a post-conflict narrative (e.g. 'sacrifice' 'victory'), the work of attempting to bind shattered bodies (both combatant and civilian) to political discourse is projected throughout conflict (which includes both 'conventional' war and prolonged and intersecting chains of terrorism, state intervention, undeclared war etc) whilst rarely accomplishing anything resembling stable meaning. I simply point here to the colossal tragedy of the ongoing Syrian conflict as exemplification.

Second, that the work of according meaning to bodies is no longer ceded to the state, but has been in some sense 'democratised' or at least made available to non-state actors, such as Iraq Body Count Project. This process includes the victims/survivors of conflict themselves. Many survivors of $7 / 7$, for example, have a complex relationship to the political narratives around the event, and 
have sought to avoid being directly recruited a singular story of the meaning of the bombings (see Brown et al, 2015). But at the same time, some survivors who have been left with significant physical challenges have found ways to align their bodies with a range of causes, typically those which have little to do with the bombings themselves, and see the use they make of their own physicality as a way of memorializing the event in a register that escapes national politics (see Allen \& Brown, 2011). The referential instability of the body here leads to personal projects that are far closer to what Scarry calls 'making' than the deconstructed form that she associates with war.

The third change has been in our critical awareness of the role of the production of affect in conflict. The morale of civilian populations became a major military issue during twentieth century conflicts (see Janis, 1951), particularly in relation to air war and 'total war' (Anderson, 2012), even if it was subject to denial during the post-conflict phase (as detailed by Sebald, 2004, in the case of Germany). However we might say of modern conflict, particularly in relation to terrorism, that the affects generated by both the actual and threatened destruction of bodies, are themselves strategic objects of violence along with bodies. Conflict produces a generalised affective referential instability in the form of circulating feelings and intensities that lack a clear objective referent or discursive anchor. The anticipation and management of the emergence of such affects - or 'premediation' as Grusin (2010) terms it - by conflicting state and non-state actors has become as important an aspect of modern conflict as the project of out-wounding the other.

\section{The Deconstructed Version (ii) - Unmaking in Torture}

Scarry's analysis of torture is quite rightly the most well-known and influential aspect of the text. In this chapter, Scarry concentrates the precision of the skills of literary analysis to a relentless, focused decomposition of the scene of torture to its constituent elements. She reads materials emerging from Amnesty and other human rights reports as though they contained the regularity of structures to be found in George Eliot's depiction of work, or Henry James' interior narratives. Scarry lays bare the essence of the relationship between the victim and the torturer in an unflinching manner. But she does this in a way that clearly returns us to the moral unambiguity of what is being considered. Torture is an obscenity that serves no immediate practical purpose and that debases our common humanity by its very existence. Worse still, it perverts or deconstructs the very basis by which our sentience finds its fragile foothold in the world. Torture is anti-creation, anti-sentience and ultimately, anti-life. Our sole interest in the matter must come from understanding how it is corrosive of all that makes us civilized beings.

The point of departure for the analysis is the recognition that torture does not and has never been an especially productive source of information for the regimes that practice it. Nevertheless, the discourse of torture as information gathering' is routinely used as part of its justification:. $\leq$

Although the information sought in an interrogation is almost never credited with being a just motive for torture, it repeatedly credited with being the motive for torture. But for every instance in which someone 
with critical information is interrogated, there are hundreds interrogated who could know nothing of remote importance to the stability or selfimage of the regime. Just as within a precarious regime the motive for arrest is often a fiction (the eggseller's eggs were too small - Greece), and just as the motive for punishing those imprisoned is often a fiction (the men, although locked in their cells, watched and applauded the television report that a military plane had crashed - Chile), so what masquerades as the motive for torture is fiction. (p. 28)

To see torture as having an ostensive practical purpose is to misunderstand how the entire juridical system operates under the 'states of emergency' through which the states that deploy it as a means of governance act. Arrest and imprisonment are not meant to punish the unjust, but rather to enforce a political settlement through establishing the absolute and entirely arbitrary power of the state. Similarly, the fact that torture is so readily applied to persons who clearly have nothing to offer to the state, and in a manner that it is so elaborate and, it must be said, resource-intensive, demonstrates that the supposed 'motive' offered for the practice is a deliberate mystification.

So what then is the function of torture, if not information gathering? Scarry discerns the presence of two major features in the reports - the reduction of the body of victim to an agonizing state of overwhelming pain and the relentless presence of the voice of interrogator. The two positions in the scene of torture are the reduction of the victim to a self without extension, a body shorn of anything beyond its own pain, and the disembodiment of the interrogator as a pure voice, seemingly outside of the physical realm, whose relentless discourse and (normally unanswerable) questions drive the entire scene. Here the words of the interrogator become tightly associated with the pain of the body, but also, perversely seems to offer a means outside of it - 'although the torturer dominates the prisoner both in physical acts and verbal acts, ultimate domination requires that the prisoner's ground become increasingly physical and the torturer's increasingly verbal, that the prisoner become a colossal body with no voice and torturer a colossal voice' (p. 57).

It is within this play of proximity and distance, acted out between voices and bodies, that Scarry uncovers the structure of torture. The interrogator 'unmakes' the world of the victim, by relentlessly turning all possible sources of selfextension against their own sentience, such that their world is now tightly concentrated on their own body. Hence the routine way in which torture adopts the codes of domesticity - that most elemental form of self-extension - and turns them against the victim, rendering them not as objectified sentience, but rather as weapons that abuse and degrade sentience:

Men and women tortured during the period of martial law in the Philippines, for example, described being tied or handcuffed in a constricted position for hours, days, and in some cases months to a chair, to a cot, to a filing cabinet, to a bed; they described being beaten with 'family-sized soft drink bottles' or having a hand crushed with a chair, of having their heads 'repeatedly banged on the edges of a refrigerator door' or 'repeatedly pounded against the edges of a filing cabinet'. The room, 
both in its structure and its content, is converted into a weapon, deconverted, undone. Made to participate in the annihilation of the prisoners, made to demonstrate that everything is a weapon, the objects themselves, and with the fact of civilization, are annihilated: there is no wall, no window, no door, no bathtub, no refrigerator, no chair, no bed. (p. 41)

I quote this last extract at length because in just under 150 words, Scarry distils the formula common to all forms of torture: the creation of a ghastly simulacrum of the home where all that shelters and sustains will now be experienced as a source of pain and the 'annihilation' - the word is perfectly chosen - of selfextension. This is 'unmaking' in its absolute form.

But this is not the end of the scene. Torture can often end with the killing of the victim. In these cases, it has no other purpose than serving as an extended demonstration of the arbitrary power of the state. The state objectifies itself to itself in its merciless and utterly obscene power to annihilate those whom pose no real threat. The ratio of its annihilative power to its supposed injuries is probably not much greater or less that the 40:1 of the conflicts between nations of the Global North and South (a fact that becomes more explicable when we understand that many of the regimes that Scarry is concerned with in this chapter were directly or indirectly sponsored by the US). But in many cases, the tortured victim is released on the condition that they must first be deemed to have 'confessed'. Hence the victim is required to assent to nonsensical or irrelevant statements, or to be taken to have done so through their inability to speak. In this way, the broken and maimed body of the victim is recruited into power, made to bear the 'insignia' of power, as the sole means through which pain can be displaced from its concentration within the body, and allowed back into the rudimentary forms of self-extension (e.g. one is allowed to sit on chair rather than being beaten by it).

As a literary scholar, it is interesting that Scarry omits from her text the great work of literature that lends support to analysis - namely Orwell's 1984. In the well-known scenes of torture that lead to the denouement of the novel, O'Brien answers Winston Smith's pleas to make sense of what is happening with the gnomic phrase 'the object of torture is torture' (p. 212). The novel suggests that the routine 'unmaking' of citizens, confronting them with the utterly arbitrary power of the state, is the means by which the state perpetuates itself. It is not necessary for there to be any coherent discourse offered to assist in remaking; the demonstration will be entirely sufficient, those who wish to return to the status of citizen will have to do their own work of rationalizing their experiences. Scarry suggests otherwise, that in torture as in war, there will be an alignment with the significations offered by the 'voice' of power, and in this alignment the body in pain will be lifted out of itself.

At this point, we need to set Scarry's analysis of torture in the context of recent work and events. Darius Rejali (2007), for example, demonstrates that whilst torture rarely extracts accurate information (and even where it does, this is often not recognised by the torturer), false information and false confessions may suit the legal and political goals of the regime that tortures just as well, not least 
because they assist in 'turning' the victim into an unwilling informant. John Conroy's (2000) case studies of the 'ordinary people' who enact torture on behalf of the state shows that instead of being mere tools in the creation of a powerful illusion, they may have a complex affective relation to their work, and to some extent believe in the efficacy of the practice, as either information extraction or useful coercion. Critically, at the time of writing The Body in Pain, torture remained something of a 'dirty secret' amongst the tools of state governance. What Scarry could not have predicted would be the explicit acknowledgement on the part of the US and its allies of the use of torture - or 'enhanced interrogation' - as a legal means of enforcing its extra-territorial power across citizens of other nations, nor of the complex web of transnational illegalities (or 'extraordinary rendition') through which this power was propagated. Scarry's analysis makes of torture a transcendent counterpoint to 'making' (this is the logical converse of creation), but at the same time seems to place it as a historical anomaly (this is what happens in states-in-transition). Does the structure of her argument still stand given our awareness of the routinisation of torture in recent times?

We need to acknowledge, first of all, that the explicit arrest and torture of citizens remains a relatively rare event in the Global North. But if we follow Scarry's analysis, the infliction of actual pain on persons is not the guiding logic of torture. It is the reduction of the individual to a pure body, shorn of selfextension that constitutes the essence of the torture scene. Understood in this way, we can see instances of this logic routinely in operation. Take, for example, the application of 'work capability assessment' in the UK. This is a statutory evaluation that has been conducted from 2008 onwards to establish whether or not a person is deemed 'fit for work' or is eligible for employment and support allowance. This assessment procedure involves asking disabled and ill individuals to engage in painful movements to demonstrate their capacities, along with answering a battery of invasive questions. It was initially out-sourced from government to the private company ATOS Health Care and, since March 2015, Maximus Health and Human Services Ltd. The evaluation has been regarded as flawed in its very conception and the introduction of private providers for the assessment - whose profitability is dependent on the number of applicants who fail the evaluations - has led to the widespread concern that the system is deliberately seeking to disqualify applicants.

Work capability assessment is not waterboarding (this needs saying). But it shares with waterboarding the logic of reducing the subject to a pure set of physical attributes. Those aspects of the assessment that require the applicant to demonstrate their capacities for movement compound this (for example, showing the assessor how far one can move across the assessment room). And these movements are in turn not indexed to the broader conditions of the person's life, but are only relevant insofar as they position the applicant in relation to the web of power relations that far exceeds their capacities to act. In short, the process bears strong similarity to how Scarry describes torture: shrink the person's life to a small zone of physical actions, demand that they perform those physical actions under aversive conditions, focus relentlessly on the body itself and discount anything the person says, make of the applicant a 'pure body', lift the signs of this body into the discourse of the voice of the interrogator/ evaluator. Small wonder then that recent statistics demonstrate increased levels 
of suicide in those areas of the UK where fitness to work has been most stringently enforced (see Barr et al, 2015). This seems to be an inevitable response to the routinisation of the logic of torture in the form of a war fought by the state against the most vulnerable in society.

\section{Endpiece}

The Body in Pain is something of a one-off, in several ways. It stands as the opening to a field of 'body studies', but despite its enormous influence it has had no obvious successor and does not give way to any particular programme of studies. The author did not follow up the text with a sequel or extend their thinking such that it acquired the status of a model. Whilst much discussed, the examples used are not directly revisited or extended by other authors. So we have something of an 'orphan' text, which in one sense stands alone by its own merits, but in another must inevitably be evaluated using the terms of reference that it helped to initiate. To use a familiar phrase, in this book Elaine Scarry opened a door to a room that she subsequently refused to enter. How to make sense of this, now, at a thirty-year remove?

Using the criterion outlined above, there are most certainly 'better' body booksiv. Judith Butler's Gender Trouble, for instance, which comes in the blink of eye of five years later than The Body in Pain, gives us the initial formulation of a notion of 'performativity' that is quite literally world-altering to the humanities and social sciences. Similarly, Foucault's notion of 'technologies of the self', which bears such a great relation to what Scarry is doing with the notion of 'self extension', is becoming known at roughly the time her text is starting to emerge. That Foucault's text is regular fixture on undergraduate curriculums, and Scarry's text a treat on extended readings list for postgraduates tells us something about nature of the networks of academic influence, I guess (although Scarry's move from Pennsylvania to Harvard is hardly a slouch).

Let me try three ways of rounding this off (sorry - if I had learnt anything from the text, it would have been five or seven ways ...). First, Scarry is one of the first authors to have seriously suggested that making - in all its dubious Heideggarian garb $^{v}$ - should be the central preoccupation of the humanities and social sciences. It has taken a long time before the implications of this suggestion have become clear, as the recent work of Tim Ingold (2013) demonstrates. But turning this concept around from where we are now, we can see that making is no longer necessarily indexed to 'the human'. As Maria Puig de la Bellacasa (2016) persuasively argues, 'making' is not the recruitment of the material world, nor the objectification of human predicates, but rather a shared labour of humans coinventing themselves through alignment with more-than-human projects in which our fates are inextricably bound. We are not the 'creators', but rather one actor in an ongoing braid of making and unmaking that draws a range of actors (both human and more-than-human) tighter together.

Second, Scarry raises the question of the referential instability of the human body but is unable to follow the huge range of implications that follow from this assertion. Indeed one of the central difficulties of The Body in Pain is that it alternates between a self-evident faith in the reduction of the body-in-itself and the infinitely malleable objectification of the body through its extensions. But the 
latter is corrosive of the former - can we ever really return to a notion of the body without external referents outside of the relatively exceptional experiences of torture? Where can we find this 'pure' body outside of acts of imagination? Nevertheless, the important lesson that Scarry teaches is around how this referential instability of the body may be recruited into diverse political projects.

Third, and finally, where should we turn to ground notions of justice? Here, again, Scarry's text is prescient - a version of the just that does not start from the brute materiality of our bodies and the ways in which they may be acted upon is scarcely worth the term. Scarry's apparent answer to this dilemma is one that both conditions and disrupts our own. She invokes not some notion of class or ethnicity, history or culture, but the brute materiality of what social arrangements do to our bodies. How may we extend ourselves? What kinds of objecfications result? How do such objectifications allow us to participate in on another's sentience? Perhaps only a tenured literary scholar could have asked such questions at the time. Perhaps only now can we see such questions as essential matters, as means by which we 'body forth' into the political.

\section{References}

Allen, M. 2015 The Labour of Memory: Memorial Culture and 7/7. Basingstoke: Palgrave Macmillan.

Allen, M. J. \& Brown, S.D. 2011. Embodiment and living memorial: The affective labour of remembering the 2005 London Bombings. Memory Studies, 4(3), 312-327

Anderson, B. 2012. Targeting Affective Life from Above: Morale and Airpower. In: Adey, P., Whitehead, M. \& Williams, A. (Eds) From Above: Verticality, Violence and Visual Culture. London: Hurst

Barr, B., D. Taylor-Robinson, D. Stuckler, R. Loopstra, A. Reeves, \& M. Whitehead 2015. 'First, do no harm': are disability assessments associated with adverse trends in mental health? A longitudinal ecological study. Journal of Epidemiology \& Community Health, doi:10.1136/jech-2015-206209

Butler, J. 1990. Gender Trouble: Feminism and the Subversion of Identity. London: Routledge.

Caro, R.A. 2015. The Power Broker: Robert Moses and the Fall of New York. New York: Vintage.

Conroy, J. 2000. Unspeakable Acts, Ordinary People: The Dynamics of Torture. New York: Alfred Knopf.

Fisher, P. 1978. The recovery of the body. Humanities in Society, 1: 133-146.

Grusin, R. 2010. Premediation: Affect and Mediality after 9/11. Basingstoke: Palgrave Macmillan.

Harman, G. 2011. The Quadruple Object. London: Zero Books.

Hoskins, A. 2004. Televising War: From Vietnam to Iraq. London: Continuum.

Hoskins, A \& B. O'Loughlin 2010. War and Media: The Emergence of Diffused War. Oxford: Polity.

Ingold, T. 2013. Making: Anthropology, Archaeology, Art and Architecture. London: Routledge.

Janis, I.L. 1951. Air War and Emotional Stress. New York: McGraw Hill.

Laqueur, T. 1990. Making Sex: Body and Gender From the Greeks to Freud. Harvard: Harvard University Press. 
Latour, B. 1992. Where are the missing masses? A sociology of a few mundane objects. In Wiebe E. Bijker and John Law eds. Shaping Technology/Building Society: Studies in Sociotechnical Change. Cambridge, Mass: MIT Press, pp. 225-258

Mol, A. 2002. The Body Multiple: Ontology in Medical Practice. Durham: Duke University Press.

Netz, R. 2009. Barbed Wire: An Ecology of Modernity. Middleton CT: Wesleyan University Press.

Puig de la Bellacasa, M. 2016. Matters of Care: Speculative Ethics in More Than

Human Worlds. Minneapolis: University of Minnesota Press.

Rejali, D. 2007. Torture and Democracy. Princeton: Princeton University Press.

Scarry, E. 1985. The Body in Pain: The Making and Unmaking of the World.

Oxford: Oxford University press.

Sebald, W.G. (2004) On the Natural History of Destruction. London: Penguin

Winner, L. 1980. Do artifacts have politics? Daedalus, 109(1): 121-126

\footnotetext{
i Scarry's use of the term 'work' rather than 'labour' draws our attention to elemental processes of energetic transformation of matter - a literal reshaping of the world - rather than the social relations which come to frame this activity.

ii It is also worth noting at this point that the idea that the 'core' of an artefact is defined by human sentience is an instance of what Object-Oriented-Ontology refers to as the error of 'correlationism' (see Harman, 2011). This approach would call into question the very idea that artefacts are to be analysed relationally in terms of their engagement with human action.

iii This phrase is often mis-attributed to Gilles Deleuze, possibly due to its citation by Hardt \& Negri.

iv Those criterion being a) the inauguration of a programme of studies; b) the formulation of concepts that can travel beyond the specific domain of the text; c) the extension of a problematic such that it acquires a formal name that authorizes an established and recognized intellectual position - e.g. 'Butlerian', 'Foucauldian' etc.

v See Heidegger's account of techne and 'making' in relation to the unconcealing of Being

(Heidegger, 1993)
} 